\title{
Some Aspects of Reducing Greenhouse Gas Emissions by Using Biofuels
}

\author{
Olga Litvak'* Serhii Litvak' \\ 1 Admiral Makarov National University of Shipbuilding, 54024, Heroiv Ukrainy Avenue, 9, Mykolaiv, Ukraine \\ * Corresponding author's e-mail: olya.litvak@gmail.com
}

\begin{abstract}
The article is devoted to a study of the issues related to the processes of reducing the greenhouse gas emissions using different types of biofuels. The dynamics of carbon dioxide emissions in the global energy sector were analyzed and it was determined that a stable level of the $\mathrm{CO}_{2}$ emissions in the last three years is due to introduction of the technologies with the use of renewable energy sources by developed countries. It was proven that the assessment of total greenhouse gas emissions requires an analysis of emissions throughout the life cycle of a biofuel. The impact of a biofuel on the climate change depends on the raw material from which it is produced, and which has a decisive influence on its chemical composition and performance. It was established that a significant role in ensuring energy security and preventing climate change is attributed to the development of biotechnologies, unrelated to the risks of agricultural production. The use of a biofuel from lignocellulose raw material may be more efficient in terms of reducing the greenhouse gas emissions. A biofuel, obtained from the processing of microalgae, also has important prospects. The ability of microalgae to bind atmospheric carbon dioxide may have a positive effect on solving the problem of greenhouse effect.
\end{abstract}

Keywords: global warming, carbon dioxide emission, low carbon economy, bioethanol, biodiesel, lignocellulose raw materials, microalgae.

\section{INTRODUCTION}

The question of climate change and global warming is an important issue for all countries of the world and requires serious solutions. The greenhouse effect phenomenon is very complex and constitutes one of the essential climatic factors. The presence of greenhouse gases creates the conditions for biological diversity, existing on the Earth. After many millions of years, the content of greenhouse gases has been set at a value, permitting to maintain thermal balance on the planet. These gases differ greatly in terms of their concentration in the atmosphere. Growing total concentration of greenhouse gases in the atmosphere leads to an increase in the greenhouse effect and, as consequence, to a rise of the global temperature.

The principal long-lived greenhouse gas in the atmosphere is carbon dioxide $\left(\mathrm{CO}_{2}\right)$. However, methane and nitrous oxide also significantly affect the air pollution. Contribution of these long-lived greenhouse gases to the global warming is as follows: carbon dioxide $\mathrm{CO}_{2}-$ about $66 \%$; methane $\mathrm{CH}_{4}$ - about $17 \%$; nitric oxide $\mathrm{N}_{2} \mathrm{O}$ - about 6.2\% [WMO, 2019]. These three gases, together with chlorofluorocarbons (CFC-12 and CFC-11), account for approximately $96 \%$ of radiative forcing due to the longlived greenhouse gases [Butler et al. 2019].

The main source of the anthropogenic $\mathrm{CO}_{2}$ emissions into the atmosphere is energy. Most of the energy, needed to produce electricity, heat buildings and operate transport, is provided by fossil fuels (oil, natural gas and coal), the combustion of which results in $95 \%$ of all anthropogenic carbon dioxide emissions to the atmosphere [Arutyunov 2001]. A considerable amount of $\mathrm{CO}_{2}$ is released during combustion and decomposition of wood, upon deforestation, as a result of land use change, soils erosion and in the process of farming. Small amounts of methane and nitrous 
oxide are released into the atmosphere during the combustion of fossil fuels. The main source of anthropogenic emissions of methane is cattle breeding; it is formed in rice fields as well as in the process of decomposition of manure and household waste in dumps without the access to oxygen. Nitric oxide is released into the air during tillage with use of mineral and organic nitrogen fertilizers.

In proportion to the growth of fossil fuel consumption, the volumes of greenhouse gas emissions increase as well, which has a negative impact on the climate of the entire planet. Therefore, the main strategy of reducing global warming is aimed at reducing the use of fossil energy carriers. The humanity is compelled to look for replacement of traditional energy sources with ecologically cleaner fuels.

The overall long-term strategy of preventing climate change is set out by Paris Climate Agreement. This document, adopted at the 21 st Conference of the parties to the United Nations Framework Convention on Climate Change (COP21), demonstrates unity and determination of the entire world community to solve the global problem [Paris Agreement 2015].

The most effective technological solutions to the problem of climate change are: transition to the use of low-carbon or non-carbon fuels; decarbonization of the electricity production; increasing the efficiency of energy production and consumption; application of carbon capture and disposal technologies; use of biofuel and other renewable energy sources. A special role is given to the task of preserving and increasing the potential for $\mathrm{CO}_{2}$ absorption in forestry and land use.

In the transition to a low-carbon economy, the use of biomass, which may serve as a renewable energy source, including thermal energy and electricity is deemed to be an attractive alternative. Biomass can be used to produce motor fuels, the use of which reduces the emissions of carbon dioxide, sulfur and heavy metals and also increases energy security as a result of replacing coal, oil and natural gas with a biofuel.

At the same time, a number of researchers connect the use of biofuel with possible negative consequences. In the first place, it is an aggravation of the food problem. This implies limitation of agricultural land and, consequently, inevitable competition of food and energy crops for land resources, negatively affecting the food security of countries and entire world.

\section{GLOBAL TRENDS IN REDUCING CARBON DIOXIDE EMISSIONS IN THE ENERGY SECTOR}

The EU countries place ever increasing demands on environmental safety standards, and their efforts are aimed at finding an alternative to traditional fossil fuel. Dependence on energy imports, high energy prices thereof, political factor, and climate changes also encourage the use of an alternative fuel.

According to the International Energy Agency (IEA), in 2019 the carbon dioxide emissions in the global energy sector constitute 33.3 billion tons. The carbon dioxide emissions in the world have not increased as compared to the previous year of 2018. Stable emissions are due to the efforts made by developed countries to abandon the coal-based energy production and switch over to renewable energy sources and natural gas (Figure 1). The most significant reduction in emissions among countries was observed in the United States: the index decreased by 140 million tons, or $2.9 \%$. Currently, the level of $\mathrm{CO}_{2}$ emissions in the United States is almost 1 billion tons below the peak value, recorded in 2000. The level of carbon dioxide emissions in the European Union decreased by 160 million tons, or $5 \%$, in 2019, while in Japan, the index decreased by 45 million tons, or about $4 \%$, which became the fastest decline since 2009 [IEAa, 2020].

Increased $\mathrm{CO}_{2}$ emissions are observed in the countries rich in fossil fuel, and in the developing countries. In 2019, the figure increased by about 400 million tons, with almost $80 \%$ of emissions falling on the countries of Southeast Asia, where the coal-based electricity production continues to grow.

\section{POTENTIAL EFFECTS OF REDUCING THE GREENHOUSE GAS EMISSIONS BY USING FIRST GENERATION BIOFUELS}

Thus, the main motivations for implementing policies to encourage use of alternative fuels are energy security and urge to reduce the greenhouse gas emissions. A wide range of biomass sources can be used for bioenergy production. Biofuel is obtained from forestry, agricultural or fishery products or from municipal waste; from byproducts and wastes of the agricultural and food industry. 


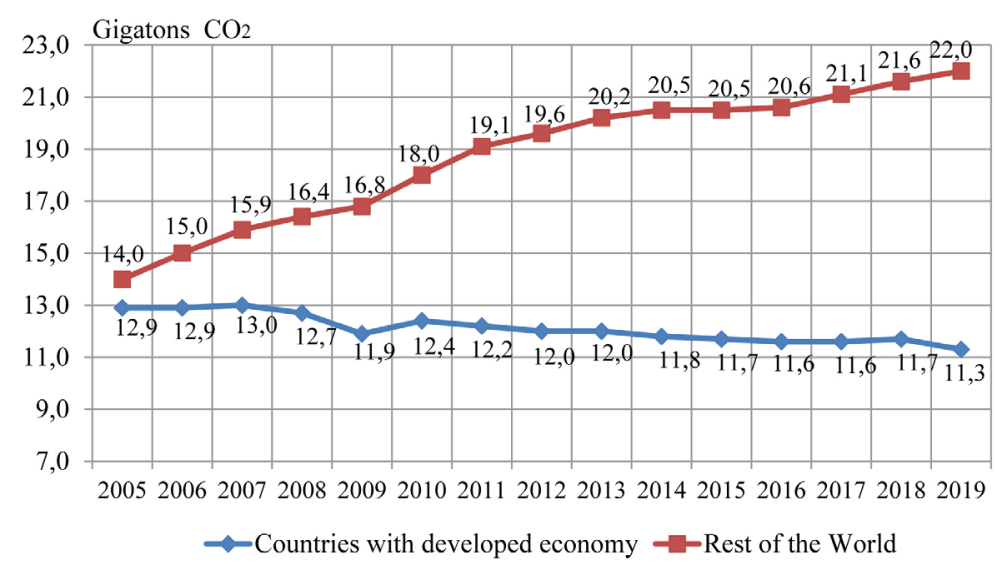

Figure 1. $\mathrm{CO}_{2}$ emissions in the energy sector of the world [IEAb 2020]

Liquid biofuels are recognized as one of the promising renewable energy sources. Increased interest in this type of biofuel is due to the growing needs of the transport sector of the economy. The most important types of such fuel are bioethanol and biodiesel. The world bioethanol production is growing by about 5\% annually. According to experts, the steady growth of fuel ethanol production will continue at least until 2030. The main area of bioethanol use is a component of motor fuel or even - a stand-alone motor fuel.

The growing interest in bioethanol is also due to the fact that it has many advantages: it is biodegradable and does not contaminate the natural water systems during spillage; it is a highly efficient fuel with octane number of 113 and significantly increases the octane number of gasoline-ethanol fuels; it also reduces the amount of harmful substances in a car engine, keeping the engine clean. The $10 \%$ addition of ethanol to gasoline reduces the greenhouse gas emission by $12-19 \%$, carbon monoxide - by $30 \%$, particulate matter in exhaust gases - by $50 \%$, carcinogenic aromatic hydrocarbons - by at least one order of magnitude. The only disadvantage of bioethanol as a motor fuel is relatively low energy-output ratio $(21-22 \mathrm{MJ} / \mathrm{l})$ as compared to gasoline (32-33 MJ/1) [Matkovskiy et al. 2010].

The production of ethanol may use any raw material, containing a significant amount of sugar, or the materials that can be converted into sugar, e.g. starch or cellulose. Ethanol, supplied to biofuel markets today, is produced as based on sugar or starch. Raw materials, traditionally used for production of bioethanol are grain, sugar beet, sugar cane and sugar sorghum.

Modern production of liquid biofuel, based on sugar and starch-containing crops (bioethanol) and oilseeds (biodiesel) is usually called as the production of the first-generation biofuel.

Raw materials, proposed for the production of first-generation biodiesel, were agricultural crops - wheat, rapeseed, soy, sunflower, corn, sugar beets, from which oils were obtained for further processing. Currently, the leading countries in the industrial production of biodiesel mainly use as raw materials rapeseed (EU), soybean (USA, Argentina, Brazil) and oil palm (Malaysia, Philippines) [Kocar et al. 2013].

Just as different crops have different biofuel yields per hectare, the energy balance indices and greenhouse gas emission reductions also vary greatly, depending on the raw material, place of its growing and the processing technology. Introduction of biofuels into energy supply depends on the energy intensity of biofuel and the energy spent on its production. Thus, the net effect of biofuels on the greenhouse gas emissions can vary significantly.

Biofuels are produced from biomass and therefore should theoretically have a neutral level of carbon dioxide emissions, as its combustion only returns to the atmosphere carbon, removed by plants from the atmosphere during their growth. This is in contrast to fossil fuels, which release the carbon that has been stored for millions of years below the earth surface [EISA 2007].

However, an estimate of total greenhouse gas emissions requires the analysis of emissions throughout the life cycle of biofuel: sowing and harvesting of agricultural crops; processing of raw material into biofuel; transportation of raw material and final fuel; storage, distribution and retail sale of biofuel, including the impact of refueling the vehicle and emissions, resulting from 
combustion. In addition, any possible by-products that may reduce emissions, should be considered as well [HLPE 2013]. Therefore, it is obviously clear that the energy balance of fossil fuel is only one of several determining factors of biofuel impact on emissions (Figure 2).

The most important factors, associated with the process of agricultural production, include the use of fertilizers, pesticides, irrigation technology and tillage. Land use change, related to the expansion of biofuel production, may have a considerable impact. For example, conversion of forest areas to produce crops for biofuel or replacement of crops with raw materials for biofuel in some areas may bring about the release of large amounts of carbon dioxide, and it will take years to restore the original state through the reduction of emissions by replacing fossil fuel with biofuel.

The potential effects of reducing the greenhouse gas emissions in use of biofuel, based on different raw materials, are shown in Figure 3. In it, consideration is given to: first, the direct effect of reducing the greenhouse gas emissions; secondly, the indirect effect with consideration of changes in use of agricultural land areas [Valin et al. 2015]. Excluding the indirect effects, the reduction of emissions reaches or exceeds $50 \%$, and varies depending on what raw materials are used to produce biodiesel and ethanol. If indirect effects are taken into account, then on the contrary, it will lead to the exhaustion of all resources for traditional production of biodiesel under the program of development of renewable energy sources [Meyer et al. 2015].

Involvement of new lands in agricultural cycles may have extremely negative ecological consequences: reduction of the areas of natural ecosystems, lowering of biodiversity, extinction of certain types of plants and animal species.
Another disadvantage of agricultural raw materials is their high cost, which is up to $80 \%$ of the cost of first-generation biodiesel [Sadeghinezhad et al. 2013]. Considerable costs will be incurred for obtaining of agricultural raw materials, caused by the need to use agricultural machinery, pesticides, fertilizers, regular work to restore the fertility of soils, selective and genetic engineering work to improve yielding capacity. The cost of liquid biofuel of the first generation varies significantly depending on the yielding capacity of industrial crops. The above-mentioned economic and environmental problems, related to production of first-generation biofuel, curtail the development of this energy sector.

In the EU countries, the requirements to crop suppliers and biofuel producers are regulated by Directive 2009/28/EC of the European Parliament and Council of Europe of April 23, 2009, on encouragement of use of energy, generated from renewable sources (RED I) [Directive 2009]. The main requirements of the Directive are: control of the actual greenhouse gas emissions throughout the life cycle of crops from which biofuels are produced (growing and harvesting, drying, storage and shipment), as well as provision of established reporting. The share of renewable energy sources in the energy balance in 2020 should reach $20 \%$ in total energy consumption and $10 \%$ in the transport sector.

The biofuel production should meet all stability criteria. For example, the RED Directive excludes the following categories of lands from the possible ones for targeted cultivation of energy biomass:

- lands with a high level of biodiversity: primary forests;

- protected environmental territories or plots, designated for the protection of rare,

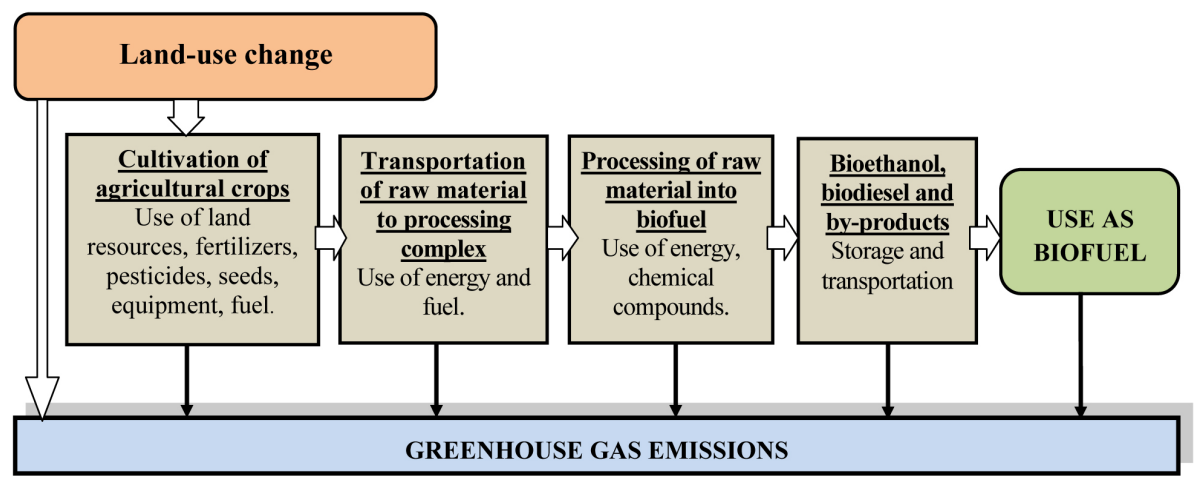

Figure 2. Life cycle of liquid biofuel with consideration of greenhouse gas balance [FAO 2008] 


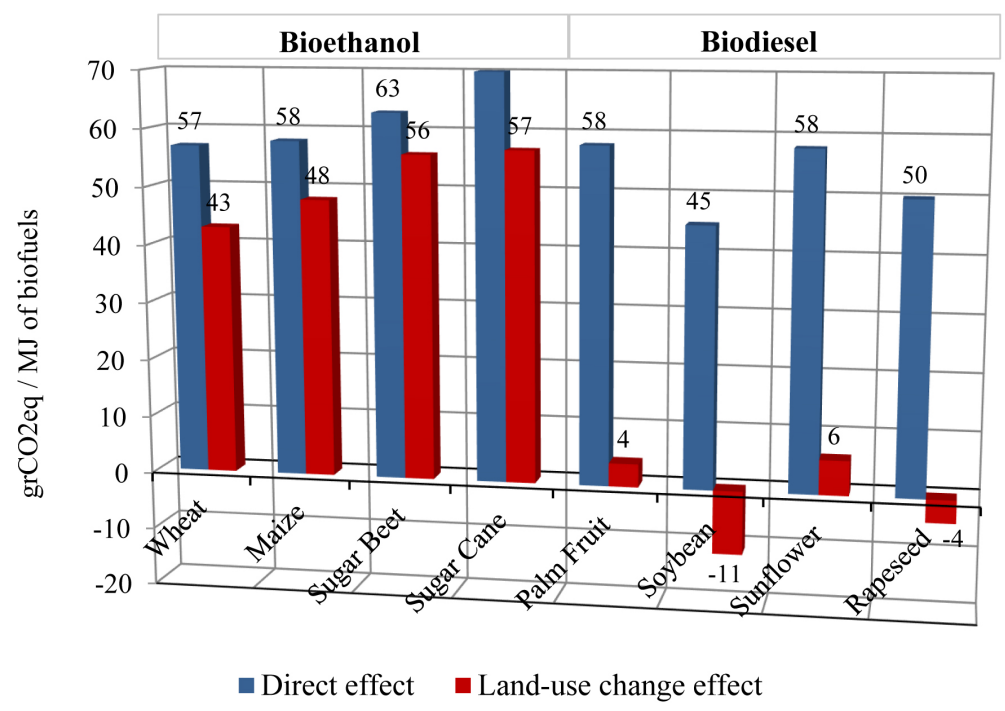

Figure 3. Reduction of greenhouse gas emissions in the European Union as a result of biofuel use [Laborde 2011]

endangered or threatened ecosystems or species, natural or artificial pastures with a high level of biodiversity;

- lands with a high level of carbon reserve: wetlands, peatlands, forested lands.

From July 2021, the restrictions on the greenhouse gas emissions from biofuel production in the EU will be more stringent in accordance with Directive 2018/2001/EU of the European Parliament and of Council of Europe on encouragement of use of energy from renewable sources (RED II) [Directive (EU) 2018]. In use of biofuel, the greenhouse gas emissions should be at least $50 \%$ less than when fossil fuels are used. After 2020, only biofuel production, contributing to the reduction of the greenhouse gas emissions and based on non-food plants and biomass, will be financed and supported by the state in EU countries. Therefore, production of second and third generation biofuel is becoming increasingly important.

\section{BIOFUELS FROM LIGNOCELLULOSE BIOMASS: ADVANTAGES AND DISADVANTAGES}

The second-generation biofuels may be produced with use of lignocellulose biomass processing technologies. The potential source includes all wastes, including agricultural and forestry wastes, processing wastes and organic components of municipal wastes [Naik et al. 2010]. Special energy crops are very promising as raw materials for the second-generation technologies.
The number of such plants includes woody plants with a short vegetation period, e.g. willow, hybrid poplar and eucalyptus, or herbaceous species, such as miscanthus, millet pampiniform [AEBIOM 2013]. These plants have important advantages over the first-generation crops in terms of their ecological sustainability. They all are able to produce more biomass per hectare of land, because the whole plant may be used as raw material for fuel. Moreover, some fast-growing perennial woody and herbaceous plants can grow on poor, depleted soils, where the cultivation of food crops is disadvantageous due to erosion or other restrictions. Both of these factors can reduce the competition for land with food and fodder producers (Figure 4).

The second-generation raw materials and biofuels can also be more efficient in reducing the greenhouse gas emissions. Most studies predict that environmentally friendly biofuel, produced from energy crops, as well as wood and agricultural waste, may considerably reduce the greenhouse gas emissions, associated with the life cycle of the first-generation petroleum fuels and biofuels [Kuptsov et al. 2015]. This is due to higher energy yield per hectare and choice of other fuel for processing. In modern production process of ethanol from first-generation biomass, the energy, used for processing, comes from fossil fuels in almost all cases (except for ethanol, obtained in Brazil from sugar cane, where most of the energy for processing is provided by sugar cane cake) [IEA, 2013]. In the case of the secondgeneration biofuels, energy for processing may be provided by plant residues, mainly lignin. 


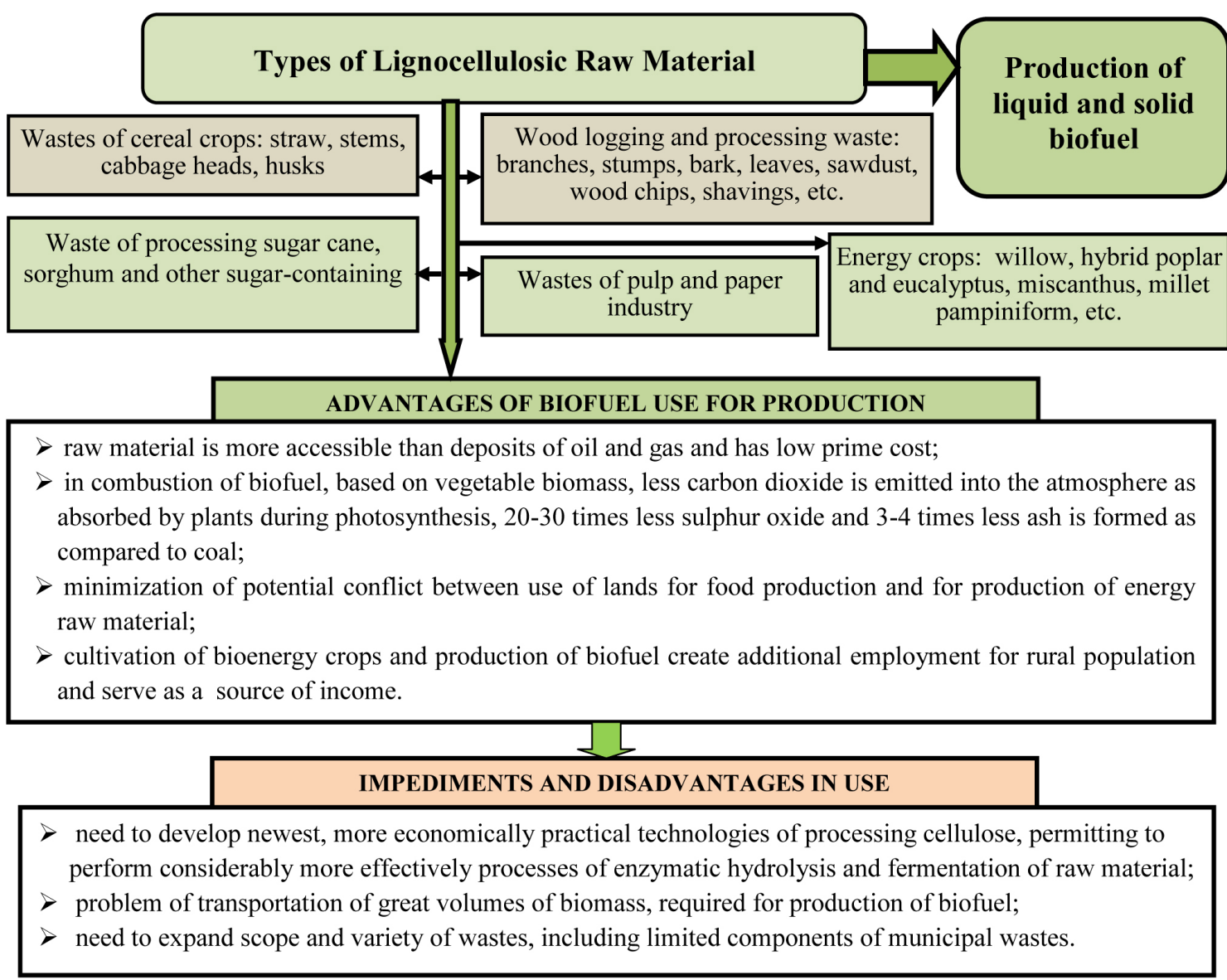

Figure 4. Advantage and disadvantages of the use of lignocellulosic raw material for the production of biofuel [Larchenko et al. 2008; Rodkin et al. 2019; Shulga et al. 2013]

The processing of cellulose into bioethanol includes two main stages: breakdown of cellulose and hemicellulose components to sugars; fermentation of the obtained sugars to obtain bioethanol. The cellulose from biowaste is the most attractive raw material for the production of high quality biofuel by fermentation. However, traditional biomass processing is an economically ineffective multi-stage process [Orzhel et al. 2019]. The main technical problem of cost-effective production of biofuel from lignocellulose is the need to reduce cost of enzymes that destroy walls of plant cells, being necessary for the production of sugar from biomass.

\section{CARBON DIOXIDE EMISSIONS AND USE OF MICROALGAE FOR BIOFUEL PRODUCTION}

The third-generation biofuel is obtained from the biomass of microalgae or heterotrophic microorganisms. Open and closed ponds, as well as photobioreactors are used for growing microalgae
[Sidorov 2010]. The costs of creating and maintaining open ponds are relatively small, but there is low biomass yield. In this case, effective cultivation of algae in open water is possible only in the regions with warm climate and intense insolation. In its turn, the technology of growing microalgae in photobioreactors can achieve significantly higher biomass yield, but has high costs for creation and maintenance [Chisti 2007]. In bioreactors, along with the need for recirculation and gas exchange in the cultivation medium, an optimum temperature should be maintained. Currently, there are several plants for the production of bioethanol from microalgae, cultivated in photobiorectors (USA, Brazil).

An additional benefit is that during cultivation, algae do not emit, but absorb $\mathrm{CO}_{2}$, being an important nutrient for them (building material) in photosynthesis. Extremely high ability of microalgae to bind atmospheric carbon dioxide may have a positive effect on solving the problem of greenhouse effect. Carbon dioxide is becoming the most important resource that may be produced on industrial basis [Choudri et al. 2015]. 
With the use of carbon dioxide at minimal water consumption, on the land unsuitable for farming, it is possible to obtain significant amounts of liquid biofuel (Figure 5).

The production of biodiesel from the biomass of microalgae is considered to be very promising from the ecological point of view, which serves as an incentive for seeking and developing the technologies to reduce its cost [Susanu 2019]. The main disadvantage of using open or closed method of microalgae cultivation is high energy consumption (as compared to the production of motor fuel from traditional raw materials), associated with such stages of biofuel production as mixing, moving suspension to the reactor, extraction, purification and the like [Kuchkina et al. 2014]. Other reasons for low economic efficiency include the lack of optimal economically sound cultivation technology permitting to obtain industrially significant volumes of microalgae biomass and processing technology of the obtained raw material.

In order to improve the properties of microalgae, genetic and metabolic engineering may be used. The attention of many researchers is focused on the development of an optimal technology. There are about 200 companies around the world that concentrate on producing fuel from algae.

Still, greater attractiveness in terms of energy efficiency and potential is offered by the technologies for the production of the 4-5th generation biofuels, being mainly in the experimental stage of development. A notable feature of the 4 th generation technologies is the production of liquid fuels from carbon dioxide and water, based on use of the genetically modified photoautotrophic bacteria (e.g. cyanobacteria) in the process of photosynthesis.

The 5th generation liquid biofuel is now considered as the most promising technological area of biofuel production. Its outstanding feature is use of microorganisms, capable of using electric current. This electrobiosynthesis technology may be used under conditions, where effective process of photosynthesis is impossible due to adverse climate (e.g. under the Arctic conditions) or there is no possibility to use large areas for the growth of photosynthetic microorganisms (remote and hard-to-access areas, cosmic space, etc.) [Strategic Research Program 2014].

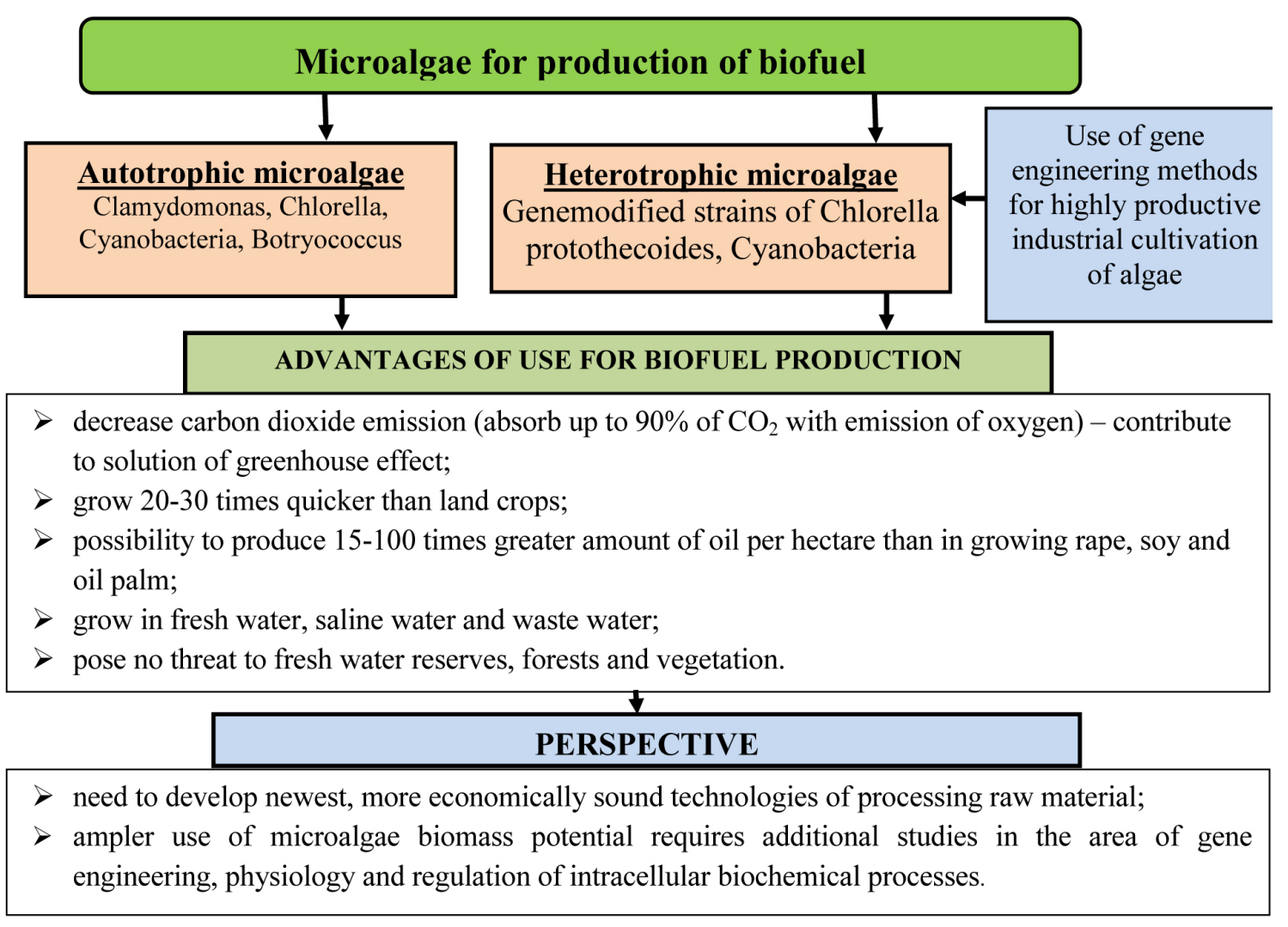

Figure 5. Use of microalgae for biofuel production and solution of greenhouse effect problem [Solodova et al. 2010; Amin-ul Mannan et al. 2017; Gouveia et al. 2009] 


\section{CONCLUSIONS}

The biofuel production is one of the fastest growing and most promising sectors of the economy. Under the conditions of expanding energy, environmental and food crisis, renewable energy sources are playing an increasingly important role as inexhaustible and environmentally sustainable.

The above data suggests that impact of biofuel on climate change may be different and depends on the raw material, from which biofuel is produced, and which has a decisive influence on its chemical composition and performance. The production of biofuel, based on cereals and oilseeds, is losing its prospectivity. A significant role in ensuring energy security is given to the development of the technologies for the production of biofuel of the second, third and subsequent generations, unrelated to the risks of agricultural production. It is obvious that production of such environmentally friendly energy carriers will not only permit avoidance of competition between bioenergy and food sector of the economy, but also will partially solve the problem of waste disposal of various industries and considerably reduce the greenhouse gas emissions.

Effective innovative technologies and comprehensive measures, aimed at low-carbon development, will permit to achieve the goals set out in Paris Agreement with regard to the mitigation of climate change consequences.

\section{REFERENCES}

1. Amin-ul Mannan M., D. Hazra, A. Karnwal, D.Ch. Kannan 2017. Algae as a platform for biofuel production - a sustainable perspective. Algologia, 27(3), 337-356.

2. Arutyunov V.S. 2001. Greenhouse effect: the problem of choosing a strategy. Russian chemical journal, 45(1), 55-63. (in Russian)

3. Butler J.H., Montzka S.A., 2019. The NOAA Annual Greenhouse Gas Index (AGGI). NOAA Earth System Research Laboratory. https://www.esrl. noaa.gov.

4. Chisti Y. 2007. Biodiesel from microalgae. Biotechnology Advances, 25, 294-306.

5. Choudri B.S., Baawain M. 2015. Bioenergy from Biofuel Residues and Wastes. Water Environment Research, 87, 1414-1444.

6. Directive 2009/28/EC of the European Parliament and of the Council of 23 April 2009 on the promotion of the use of energy from renewable sources and amending and subsequently repealing Directives 2001/77/EC and 2003/30/ EC. Official Journal of the European Union. 05.06.2009. L 140.

7. Directive (EU) $2018 / 2001$ of the European Parliament and of the Council of 11 December 2018 on the promotion of the use of energy from renewable sources (recast). Official Journal of the European Union. 21.12.2018. L 328.

8. AEBIOM (European Biomass Association) 2013. European Bioenergy Outlook 2013. Statistical Report. Brussels.

9. FAO (Food and Agriculture Organization of The United Nations) 2008. The state of food and agriculture 2008. Biofuels: Prospects, Risks and Opportunities. Rome, 55-56.

10. Gouveia L., Oliveira A.C. 2009. Microalgae as a raw material for biofuels production. Journal of Industrial Microbiology \& Biotechnology, 36, 269-274.

11. HLPE (High Level Panel of Experts) 2013. Biofuels and food security. A report by the High Level Panel of Experts on Food Security and Nutrition of the Committee on World Food Security, Rome.

12. IEA (International Energy Agency) 2013. Tracking clean energy progress. https://www.iea.org/ publications.

13. IEAa (International Energy Agency) 2020. Global CO2 emissions in 2019. https://www.iea.org/ articles/global-co2-emissions-in-2019.

14. IEAb (International Energy Agency) 2020. Energy related CO2 emissions, 1990-2019. https://www.iea.org/data-and-statistics/charts/ energy-related-co2-emissions-1990-2019.

15. Kocar G., Civas N. 2013. An overview of biofuels from energy crops: Current status and future prospects. Renewable and Sustainable Energy Reviews, 28, 900-916.

16. Kuchkina A.Yu., Sushchik N.N. 2014. Feedstocks, methods and perspectives of biodiesel production. Journal of Siberian Federal University. Biology, 1(7), 14-42. (in Russian)

17. Kuptsov N.S., Popov E.G. 2015. Energy plantation. Energy Plants Handbook. Minsk. (in Russian)

18. Laborde D. 2011. Assessing the land use consequences of European biofuels policies. Report by ATLASS Consortium for DG TRADE under Framework Contract TRADE/07/A2, Brussels, 2011.

19. Larchenko K.A., Morgun B.V. 2008. Bioethanol as an alternative renewable energy source. Biotechnologia, 1(4), 18-28. (in Ukrainian)

20. Matkovskiy P.E., Yarullin R.S., Startseva G.P., Sedov I.V., 2010. Bioethanol: technologies of obtaining from renewable vegetable raw material and areas of application. Alternative Power Engineering and Ecology, 6 (86), 95-104 (in Russian).

21. Meyer S., Schmidkhuber J., Barrero-Herl J. 2015. 
Global trade of biofuel: use of resources and greenhouse gas in the absence of common policy. Trade Policy, 1(1), 172-198.

22. Naik S., Goud V.V., Rout P.K., Dalai A.K. 2010. Production of first and second generation biofuels: A comprehensive review. Renewable and Sustainable Energy Reviews, 14, 578-597.

23. Orzhel O. et al. 2019. Green Paper. Regulation of production of liquid motor fuels. Kyiv. (in Ukrainian)

24. Rodkin O.I., Chernenok E.V., Saevich K.F. 2019. The perspective of biofuel production on the base of energy crops. Economic and environmental aspects. Scientific journal NRU ITMO. Series "Economics and Environmental Management", 1, 33-44. (in Russian)

25. Sadeghinezhad E., Kazi S.N., Badarudin A., Oon C.S., Zubir M.N.M., Mehrali M. 2013. A comprehensive review of bio-diesel as alternative fuel for compression ignition engines. Renewable and Sustainable Energy Reviews, 28, 410-424.

26. Shulga S.M., Tigunova O.O., Blyum Ya.B. 2013. Lignocellulose as an alternative raw material for the production of biobutanol. Biotechnologia Acta, 6(2), 9-20. (in Ukrainian)

27. Sidorov Yu.I. 2010. Photobioreactors. Biotechnolo- gia, V.3, 5, 19-30. (in Ukrainian)

28. Solodova N.L., Terentieva N.A. 2010. Little about biofuels. Vestnik of Technological University, 11, 348-358. (in Russian)

29. Strategic Research Program 2014. Technological Platform "Bioenergetika", http://tp-bioenergy.ru/ upload/file/spi/spi2014.pdf. (in Russian)

30. Susanu A. 2019. Regulation of liquid biofuel market in Russia and world. Trade Policy, 1/17, 60-88 (in Russian).

31. EISA (The Energy Independence and Security Act) 2007. Public Law 110-140-DEC. 19, 2007. 110th United States Congress.

32. United Nations Framework Convention on Climate Change 2015. FCCC/CP/2015/ L.9/ Rev.1. Paris Agreement. Paris.

33. Valin H. et al. 2015. The land use change impact of biofuels consumed in the EU. Quantification of area and greenhouse gas impacts. A cooperation of Ecofys, IIASA and E4tech. Netherlands.

34. WMO (World Meteorological Organization) 2019. WMO Greenhouse Gas Bulletin. The State of Greenhouse Gases in the Atmosphere Based on Global Observations through 2018, No. 15 (25 November 2019). 